\title{
SOME RECENT APPLICATIONS OF ELECTRON \& OPTICAL MICROSCOPY TECHNIQUES TO STUDY PHASE TRANSFORMATIONS IN STEELS
}

\author{
G. Spanos*, M. V. Kral**, and A. W. Wilson***
}

*Naval Research Laboratory, Code 6324, Washington, DC 20375-5000.

**University of Canterbury, Department of Mechanical Engineering, Christchurch, New Zealand. ***Boeing Satellite Systems, Inc., El Segundo, CA 90009-2919.

Within the last decade, a number of new microscopy techniques have become available which greatly enhance our ability to study phase transformations in alloy steels. These techniques include 3-D reconstruction and analysis by optical microscopy in conjunction with advanced computer techniques (e.g., see [1,2]) and automated Electron Backscatter Pattern Analysis (EBSD) [3]. It is especially powerful to couple these techniques with conventional scanning electron microscopy (SEM) and transmission electron microscopy (TEM). This paper will describe one example of some recent efforts at the Naval Research Laboratory to comprehensively combine these techniques for the study of austenite decomposition to Widmanstatten ferrite in an Fe- $0.12 \% \mathrm{C}-3 \% \mathrm{Ni}$ steel isothermally reacted at both $650^{\circ}$ and $600^{\circ} \mathrm{C}$ for reaction times ranging from $3-5 \mathrm{sec}$.

The examples presented here are for what appear in two dimensions to be secondary Widmanstatten ferrite sideplates, i.e. ferrite sideplates developed from a ferrite allotriomorphic film on a prior austenite grain boundary - see Fig. 1a. The first steps in the computerized 3-D reconstruction procedure were to make a 3-D stack of 43 such serial section images with 0.3 micron spacing between them, and to register them using NIH Image ${ }^{\mathrm{TM}}$ software. Adobe Photoshop ${ }^{\mathrm{TM}}$ software was then used in this case to trace ("mask") the ferrite boundaries (Fig. 1b) and fill the ferrite regions such that the ferrite was black and the austenite was white (Fig. 1c). IDL ${ }^{\text {TM }}$ software was then used to make a $3-\mathrm{D}$ reconstruction in which the ferrite phase is opaque gray/white and the austenite phase is transparent - Fig. 2. The ferrite "sideplates" have a complex geometry with undulations sticking out from some of the precipitates (Fig. 2). TEM of similar morphologies from the same alloy have shown that the secondary ferrite precipitates corresponding to the 3-D structures shown in Fig. 2 are not monolithic single crystals but are instead composed of many individually nucleated ferrite crystals with misorientations between them ranging from about $1-10^{\circ}[4]$ - see Fig. 3.

Automated EBSD was performed on the same types of microstructures, and misorientation maps indicate that these precipitates are evolving toward a common orientation as they develop and extend toward the center of an austenite grain - see Fig. 4. The brief examples shown here demonstrae the usefulness of combining 3-D techniques with 2-D TEM and automated EBSD orientation mapping to elucidate microstructural evolution in steels.

\section{References}

1. M A. Mangan and G.J. Shiflet, in "Solid-Solid Phase Transformations", eds., Johnson et al., TMS, Metals Park, OH, pp. 47 (1994).

2. M. V. Kral and G. Spanos, Acta Materialia , v. 47, 711-724 (1999)

3. W. Wilson and G. Spanos, Materials Characterization, v. 46, pp. 407-418 (2001).

4. G. Spanos and M. G. Hall, Metall. and Materials Trans. A , 27A, pp. 1519-1534 (1996). 

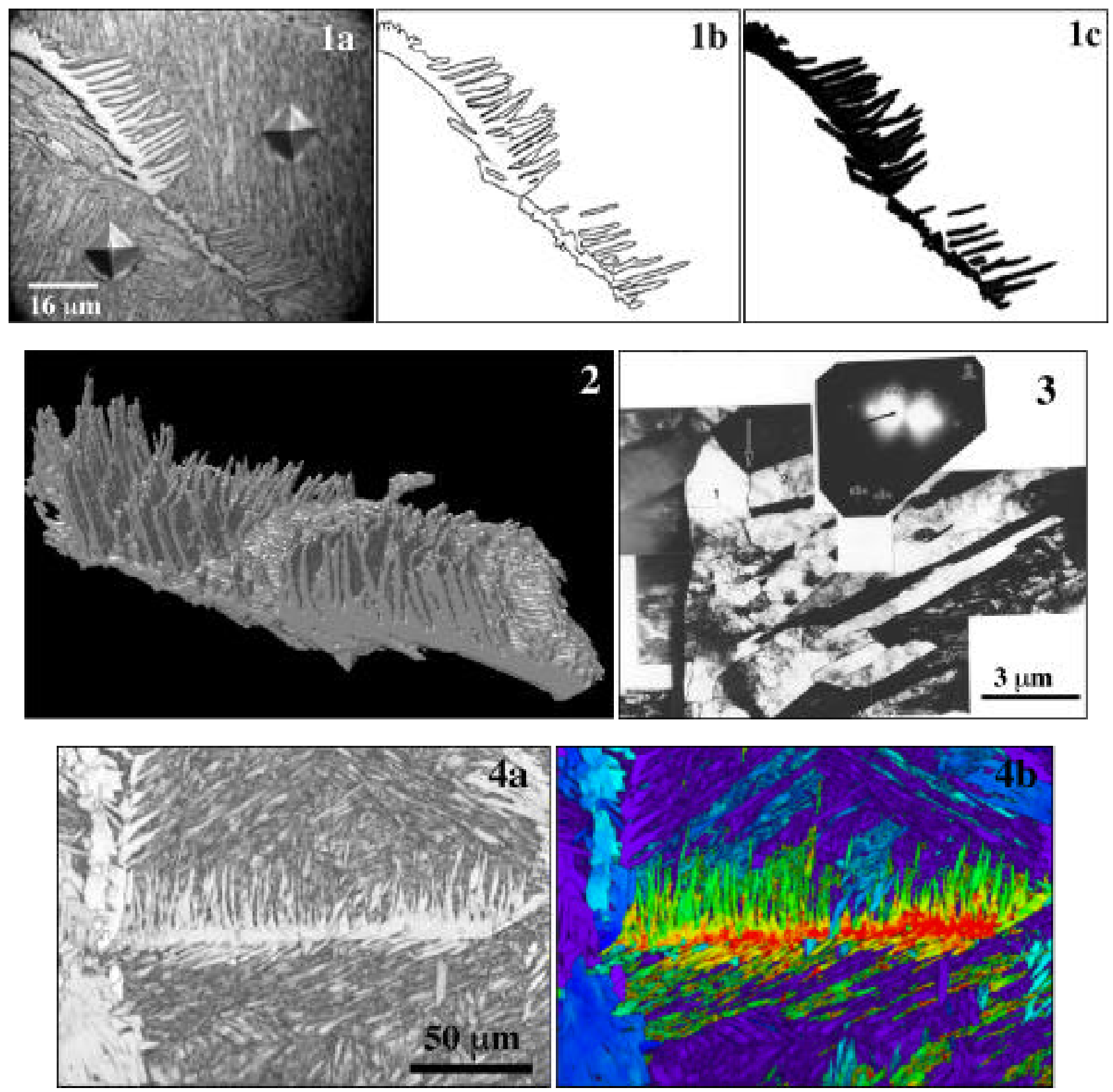

Fig. 1: Ferrite secondary sideplates. (a) Optical micrograph, (b) masked image, and (c) filled image. Fig. 2: Three dimensional reconstruction from 43 sections from the same area shown in Fig. 1. Fig. 3: TEM image from a similar microstructure in the same alloy (taken from reference [5]). Fig. 4: Automated EBSD maps. (a) Pattern quality (also called “ image quality”) map.

(b) misorientation map with misorientation scale inset. 